\title{
Coastal Communities' Attitudes towards Conservation of Freshwater Turtle in Ampara District
}

\author{
S. Kirupakaran and S. Thiruchelvam ${ }^{1}$ \\ Postgraduate Institute of Agriculture \\ University of Peradeniya \\ Peradeniya, Sri Lanka
}

\begin{abstract}
Conservation of turtle requires adequate scientific understanding of the status and dynamics of the population and consideration of the coastal communities' attitudes towards conservation of this species. Therefore, this paper explores the attitudes and knowledge of coastal communities towards the freshwater turtle and their views about conserving them in three coastal divisional secretariat divisions in Ampara district. A survey was conducted with 50 randomly selected coastal community villages in 2008. Logistic regression and Chi-square test were used to provide empirical insight of the research problem.
\end{abstract}

Average age and education of the respondents were 39 and 9 years respectively. About $67 \%$ of them were below the poverty line of Rs.2,233.00 (Real total expenditure/ person/ month). About 69, 30 and $11 \%$ of the total respondents were poaching freshwater turtle for their own consumption, selling and hobby, respectively. In general, coastal communities had a low level of awareness and knowledge on the fresh water turtles. About 49 and $45 \%$ of the respondents have seen live fresh water turtles less frequently and believed their endangered nature, respectively. Age, education and interest on nature had positive and significant relationships with their willingness to support conservation of fresh water turtles. The coastal communities expressed their positive attitude towards participatory conservation of fresh water turtles. However, it was not their priority concern. Awareness program and community participation in the conservation efforts are needed to protect the valuable endemic fresh water turtles in the Eastern Sri Lanka.

Key words: Attitudes, Coastal Communities, Conservation, Eastern Sri Lanka, Freshwater turtle

\section{INTRODUCTION}

The world is rapidly losing its biodiversity as species become extinct at an unprecedented rate. Much of this loss is occurring in the developing world, where the expansion of agriculture into frontier areas, poaching, and weak enforcement of protective measurers. In 
2004 a group of researchers from China, Thailand, the Philippines and Vietnam attempted to answer the following questions: how do people in developing countries feel about conservation of endangered ${ }^{2}$ species? Are they willing to participate in the conservation of these species? and what are the determinants of their willingness to participate in the conservation of endangered species? (EEPSEA, 2008). Such studies on endangered species have not been carried out in Sri Lanka in the past.

The research reported in this paper tries to fill this void focusing on the importance of fresh water turtle conservation in Eastern Sri Lanka. An endangered species conservation programme can generate a wide variety of use and non use values. Contingent valuation methods $^{3}(\mathrm{CVM})$ were most widely used to quantify public preference and willingness to pay (WTP) for endangered species conservation (Loomis and White, 1996). Critics of CVM claim that stated WTP for preserving endangered species does not relate to economic choice behaviour but reflects more on the purchase of good on moral satisfaction. Thus scope or size of the research, therefore, would not matter (Kahneman and Knetsch, 1992). WTP depends on the local source of income. The application of CVM in developing countries on endemic species is scant. (Tisdell et al., 2005). Due to poor income of the costal communities and their dependence on coastal resources for their livelihood and their interactions with endangered species such as freshwater turtles which threatened become critically endangered in the future, coastal communities' willingness to participate rather payment towards endangered species conservation was considered in this study. Turtle has use values like meat and egg, and nonuse values like existence value e.g. biodiversity preservation to humans. Throughout the world, marine turtles are hunted and butchered for their flesh and shells. Over harvesting for crafting, jewelry, and ornaments during the $20^{\text {th }}$ century caused a sharp decline in hawksbill turtle population, raising concerns for the species survival (Meylan and Domnely, 1999). As results of this global over exploitation, these species have become endangered. Trade in the endangered species has been banned under the Conservation on International Trade in Endangered Species of Wild Fauna and Flora (CITES). The Marine Turtle Specialist Group of the World Conservation Union (IUCN) on the other hand opposes such trade on the grounds that the species are critically endangered (Tisdell et al., 2005). In Sri Lanka, all sea turtles and their products are fully categorized under the Flora and Fauna Protection Ordinance. Freshwater turtle also comes under this protection ordinance. Sri Lanka is one of the countries in the world that has three major types of chelonians ${ }^{4}$, the freshwater terrapins, land tortoises and marine turtles. Sri Lanka is believed to harbor four fresh water turtle species namely Lissemys punctata punctata, Melanochelys trijuga parkeri, Melanochelys trijuga thermalis and Trachemys scripta. Out of which last three species are intensively harvested for flesh. Sri Lanka has only one territorial chelonian, the Star tortoises, which are considered to be one of the most beautiful tortoises in the world (Turtle Conservation Project, 2003).

There are number of turtle species namely Caretta caretta, Chelonia mydas, Eretmochelys imbricate, Melanochelys trijuga thermalis, Geochelone elegans, Lissemys punctata punctata,

\footnotetext{
2 A taxon is endangered when it is not criticality endangered but is facing a very high risk of extinction. A talon is extinct when there is no reasonable doubt that its last individual has died. A taxon is vulnerable when it is not critically endangered or endangered but is facing a high risk of extinction in the medium future (IUCN, 2004).

3 CVM is a survey approach research an induce respondents to state the preference for specified goods in a hypostatical situation rather than the observing actual payment behaviours in real market.

4 The word 'turtle' is used commonly for all chelonians despite the habitat.
} 
Melanochelys trijuga parkeri and Trachemys scripta.existing in the coastal areas which are endemic in the Eastern Sri Lanka (IUCN - Sri Lanka, 1999). However, the fresh water turtles have been reduced over time and are under the threat from sporadic poaching for domestic consumption, loss of nesting areas and feeding areas, predators, catching by fishermen and their ingestion of synthetic materials (IUCN, 2004). The turtle conservation project (TCP) in Rekawa South Sri Lanka is successfully facilitating the sustainable marine turtle conservation with the community participation and introducing a nature tourism programme called "Turtle Watch" as a self sustaining event (Kapurasinghe, 2006).

Aside from the natural scientific component, a workable framework for the management of living resources such as turtles requires an understanding of the socio-economic components. The attitudes, concerns and aspirations of the coastal communities should be assessed on what they think about the resource, whether they would like to protect, whether they think about the sustainable use, and their willingness in conserving the endangered species. However, less research efforts have been placed in promoting better knowledge and understanding of the importance of conserving valuable coastal habitats and ensuring the coastal resources are utilized in a sustainable manner.

In the above context, this explorative study focuses on the fresh water turtle's nature of existence and conservation from the point of view of coastal communities in the villages surrounding the Ampara lagoon in the Eastern Sri Lanka. Specifically this research investigates the coastal communities' nature interest, knowledge about endangered species and attitudes and willingness to participate in conservation of environment and freshwater turtle in the Ampara district. A special attention was paid to explore the determinants of the coastal communities' willingness in participating in a freshwater turtle conservation programme. The main hypothesis of this study was that poor coastal comminutes' low nature interest, poor knowledge and attitudes towards freshwater turtle, which is an endangered species were likely to result in neutral willingness to support for its conservation programme,

\section{METHODOLOGY}

Ampara district was selected due to the attractiveness of the landscape and its proximity to existing tourist destination Ulla beach in Pottuvil. Due to this freshwater turtle conservation with local community support was considered important and there has been no information about fresh water turtle in Ampara district. Three major turtle rookeries turtle nesting sites in three coastal villages were selected from the Ampara district.

Respondents were selected from one village each in three coastal divisional secretariatsdivisions in Ampara district namely Samanthurai, Karaitivu and Kalmunai. A questionnaire survey was conducted to obtain the data for this study from randomly selected 50 Tamil speaking members. Sixteen to 18 individuals were selected randomly from three villages in the three divisional secretariat divisions in 2008. The survey instrument included an extensive set of knowledge and attitudinal questions to assess the relationship between respondents' socio-demographic and economic variables and willingness to participate in freshwater turtle conservation programme. To get further insight into biodiversity and coastal management issues, key informant interviews were also held with the environmental officer of the district and Grama Niladaris in the three villages. During the survey and to create clear understanding on the endemic species, photos of different species of turtle existing in 
the area were shown to the respondents. This identified following people as the poachers who involved in catching freshwater turtle for consumption, selling and medicinal purposes. It was hypothesized that these poachers probability of willingness to participate in the freshwater conservation was associated with age (AG in yrs.), education attainment (ED in yrs.), civil status (MA married =1), family size (FS in numbers), employment type (EX experience in fishing years), monthly income / person (IN Rs/month), nature interest (NI scale) and $\varepsilon$ error term. Following binomial logit model was used for empirical estimation:

$$
\begin{aligned}
\log (\mathrm{Pi} /(1-\mathrm{Pi}))= & \alpha+\beta_{1} \mathrm{AG}+\beta_{2} \mathrm{ED}+\beta_{3} \mathrm{MA}+\beta_{4} \mathrm{FS}+\beta_{5} \mathrm{EX}+ \\
& \beta_{6} \mathrm{NI}+\beta_{7} \mathrm{EN}+\varepsilon
\end{aligned}
$$

To elicit the respondents' knowledge and attitude towards the endangered nature of freshwater turtle conservation, ten statements were presented and the respondents were asked to state their opinions on a scale of 5 to 1 , with 5 as 'strongly agree' and 1 as 'strongly disagree'. The average value and the standard deviation were used to form a scale of 1 to 3 levels i.e. low, medium and high nature interest. Similar scale was used to assess the willingness of the respondents in participating freshwater conservation. Further it was hypothesized that education and awareness campaign be likely to increase the coastal communities' willingness to participate in freshwater turtle conservation programme. Chisquare analysis was used to find the association between conservation and socio-economic variables.

\section{RESULTS AND DISCUSSION}

\section{Socio - economic characteristics of the coastal community}

All respondents were Tamil speaking community and 70, 20 and $10 \%$ of them were belonging to Christian, Hindu and Muslim religions, respectively. This reflects the variations in religion, culture and familiarity with fresh water species. The mean age of the respondents was 39.33 years and ranged between 29 and 50 years and $65 \%$ of them were married. The average educational level was 9 years. The mean household size was around $6-9$ persons, with a mean of less than four persons under 15 years of age. The average household income was Rs. 5,908.00 per month (less than 2 US\$/day) and about $67.56 \%$ of them were below poverty line of Rs. 2,233.00 (real total expenditure / person / month). About 87, 8 and 5\% of the total respondents were poaching freshwater turtle for self consumption, selling and hobby respectively. The main occupation of the people in these three villages was fishing on fulltime basis.

\section{Coastal communities' nature interest, knowledge and attitudes towards freshwater turtle}

In terms of the five most important issues related to nature and human impact on the natural environment, the respondents did not give much weight to conservation of endangered species such as freshwater turtle (Table 1).

Among the environmental issues, respondents ranked water pollution (42\%), solid waste $(30 \%)$, and habitat degradation (20\%) as the problems that affect their daily life. It was found that a large majority (73\%) of participants were unaware of the endangered nature of the freshwater turtles. Of those who know about its endangered nature and existence, the knowledge of the majority was poor. The poor knowledge of the freshwater turtle highlights 
the need for coastal communities' education about this species and others that are endangered. Otherwise, this species could disappear without most of the public being aware of it prior to its extinction. Only $2 \%$ of them considered endangered species conservation was important in the Ampara district. It is important to obtain the support of the coastal community to change the status of species from endangered to 'vulnerable' than 'critically endangered'. An observation and discussion with environmental concerned officers and people on the threats to the inland biodiversity reveals high impacts in the mangroves and lagoon area from habitat degradation in the Ampara district.

Table 1. Coastal communities' opinion on the most important environmental problems in Ampara

\begin{tabular}{lccc}
\hline Problem & $\begin{array}{c}\text { Number of } \\
\text { espondents }\end{array}$ & Percentage & $\begin{array}{c}\text { Importance } \\
\text { rank }\end{array}$ \\
\hline Water pollution - discharge of waste. & 21 & 42 & 1 \\
Solid waste pollution - garbage & 15 & 30 & 2 \\
disposal. & 10 & 20 & 3 \\
Habitat degradation - encroachment. & 03 & 06 & 4 \\
Coastal erosion - & & & 5 \\
Shell, coral \& sand mining. & 01 & 02 & 5 \\
Endangered species - pouching. & & & \\
\hline
\end{tabular}

Respondents were asked to choose one endangered species that deserve of protection from five species in Ampara district namely, freshwater turtle (e.g. Flaps shell turtle), marine turtle, mangroves, Mugger crocodile and terrestrial (Star tortoise). Results show that, fresh water turtle was ranked as the first priority. Table 2 reveals that coastal community's familiarity and knowledge about the fresh water turtles.

Table 2. Coastal communities' familiarity and knowledge about freshwater turtles

\begin{tabular}{lc}
\hline Statements & $\begin{array}{c}\text { Answered Yes (\%) } \\
(\mathbf{n = 5 0 )}\end{array}$ \\
\hline Have seen live freshwater turtles & 57 \\
Have eaten freshwater turtle eggs or meat & 21 \\
Endangered nature of freshwater turtles & 49 \\
Freshwater turtles lay their eggs on land & 85 \\
Knowledge about freshwater turtle life cycle & 77 \\
\hline
\end{tabular}

Respondents do not eat turtle meat but only $21 \%$ collect and eat the eggs. Many of them believed that turtle eggs have medicinal value. About $57 \%$ of the respondents had seen the freshwater turtle regularly but $49 \%$ of them believed that the frequency was very less compared to what they have seen 10 years before. About $77 \%$ of the respondents indicated their knowledge on freshwater turtle existence and its value of protection for poor coastal community. Respondents said that they consume turtle eggs very eagerly because they could get a chance to eat them just once a year only. This confirms that, coastal community's familiarity with turtles and 'used' turtle or consumed fresh water turtle which are now classified as 'endangered'. Since majority of the coastal communities' income is below the poverty line they consume turtle meat and eggs. This indicates that, turtle conservation can succeed only if it is done through means that protect people's livelihood rights rather than those of a single endangered species. One of the major threats for the turtles nesting was 
poaching of eggs by humans, dogs, jackals etc. Respondents mentioned that incidental turtle catch during fishing, sand mining and pollution of the water bodies cause loss of turtle number over time. Majority (90\%) of the respondents strongly agreed that it is everyone's duty to protect the endangered plants and animals for the future generation and sustainability of the ecosystem.

The coastal communities' willingness to participate in the conservation of freshwater turtle

Respondents were asked to state whether they 'strongly like', 'like', 'dislike' or strongly dislike taking part in a community-based freshwater turtle conservation programme. Of the total respondents interviewed, 12 and $46 \%$ of the respondents had high and average interest to obtain information and participate in community fresh water turtle conservation programme respectively (Table 3). Although a large majority $(92 \%)$ of the respondents expressed positive attitudes towards participatory conservation of turtle, it was not their priority concern. It was also confirmed that, the promotion of local biodiversity can be successful providing that the use of innovative practical, culturally sensitive and attractive approaches. It was believed that, it is possible to generate additional benefits from conservation of freshwater turtle and local biodiversity via nature tourism especially, when knowledge awareness and human capacities are improved.

\section{Table 3. Coastal communities' willingness to participate in freshwater turtle conservation in Ampara district}

\begin{tabular}{lcr}
\hline Statements & Responses n & (\%) \\
\hline Strong willingness to participate & 6 & 12 \\
Average willingness to participate & 23 & 46 \\
Less willingness to participate & 17 & 34 \\
Neutral and negative willingness to participate & 04 & 8 \\
Total & 50 & 100 \\
\hline
\end{tabular}

Results of the Pearson's chi-square test (Table 4) revealed that there is a significant association between the level of interest in participatory turtle conservation and the level of education of the respondents.

Similar analysis between the income and collective behavior did not show any significant association. This confirms the argument that preserving endangered species does not relate to economic behaviour but reflects more the good moral satisfaction. Table 4 shows that $42 \%$ of the respondents had medium level of interest on nature followed by 34 and $24 \%$ level of high and low nature interest, respectively.

Table 4. Coastal communities' nature interest

\begin{tabular}{lcccc}
\hline $\begin{array}{l}\text { Years of } \\
\text { education }\end{array}$ & \multicolumn{4}{c}{ Level of interest on nature and freshwater turtle } \\
& Low & \multicolumn{4}{c}{$\begin{array}{c}\text { conservation porgramme } \\
\text { Medium }\end{array}$} & $\begin{array}{c}\text { High } \\
\text { Total }\end{array}$ \\
\hline Less than 7 yrs & $5(31.3)$ & $7(43.7)$ & $4(25)$ & $16(100)$ \\
$\leq 7-\leq 10$ yrs & $7(31.8)$ & $9(40.9)$ & $6(27.3)$ & $22(100)$ \\
$\geq 11$ years & $0(0)$ & $5(41.7)$ & $7(58.3)$ & $12(100)$ \\
Total & $12(24)$ & $21(42)$ & $17(34)$ & $50(100)$ \\
\hline
\end{tabular}

Figurers in parentheses are percentage of horizontal summation 
Chi-sq. $=12.31 \mathrm{p}$-value $=0.010$

Determinants of the coastal communities' willingness to participation in fresh water conservation in Ampara district

Results of the logistic regression analysis shown in Table 5 indicate that respondents' characteristics such as education level of education, years of experience in fishing and interest on nature have positive influence on the fresh water turtle conservation programme significantly at 0.05 probability level.

Variable age was significant but negatively influences the conservation programme. This indicates that individuals who are willing to participate in conservation fall with increase in age. This may be due to older people think that they will not live to enjoy the benefits of preserving resources for later years. It implies that it is important to aim on younger generation for biodiversity conservation. The socio-economic characteristics of respondents can be used to predict the probability of their willingness to participate in freshwater turtle conservation. These findings were consistent with those of Tisdell et al., (2005). Positive values for other variables namely income, family size and marital status were not significant and reflect that they do significantly influence in the willingness to participate for turtle conservation programme.

Table 5. Logistic regression analysis of coastal communities' determinants of willingness to participate in fresh water turtle conservation programme in Ampara district

\begin{tabular}{lcccc}
\hline & $\begin{array}{l}\text { Odds } \\
\text { Ratio }\end{array}$ & $\begin{array}{c}\text { Std. } \\
\text { Error }\end{array}$ & $\mathbf{z}$ & $\mathbf{p}>\mathbf{z}$ \\
\hline Constant & 2.2120 & 1.0300 & 1.64 & 0.231 \\
Age & $-0.0849^{*}$ & 0.0728 & 1.92 & 0.064. \\
Edu. Yrs, & $0.1623^{*}$ & 0.0846 & 1.21 & 0.020 \\
Marital status & 0.7972 & 0.5190 & 0.07 & 0.796 \\
Years of fishing & $0.1326^{*}$ & 0.1828 & 1.92 & 0.052. \\
Family size & 0.0012 & 0.0131 & 1.21 & 0.356. \\
Nature Interest & 0.0427 & 0.0148 & 0.31 & 0.0627 \\
Low & $0.0626 *$ & 0.0073 & 0.55 & 0.0415 \\
Medium & $0.0976^{*}$ & 0.0041 & 0.20 & 0.0416 \\
High & 0.2120 & 0.0300 & 1.64 & 0.0314. \\
Monthly Income & & & & \\
\hline * Significant at $\mathrm{p}<0.05$, Number of observations $=50$ &
\end{tabular}

* Significant at $\mathrm{p}<0.05$, Number of observations $=50$ 
It was found that about 24, 42 and $34 \%$ of the respondents had nature interest measured on a scale as low $(<3)$ medium $(<3-7.5)$ and high $(>7.5)$, respectively. Logistic regression analysis with three levels of interest on nature indicates a higher probability (0.0977) of willingness to participate in freshwater turtle conservation programme if the interest on nature of the person is high. This suggests that relatively higher interest on nature would increase participation more in freshwater turtle conservation programmes

\section{CONCLUSIONS}

The main rationale of this study was to determine whether poor coastal comminutes' low nature interest, poor knowledge and attitudes towards freshwater turtle, which is an endangered species were likely to result in less willingness to support for its conservation programme. Results do not support this hypothesis.

It was found that large majority (73\%) of participants was unaware of the endangered nature of the freshwater turtles and its conservation was a relatively low priority for them. But when information was provided to the respondents on the importance of its conservation a large majority $(76 \%)$ of the coastal community favoured the conservation of freshwater turtles. Since majority of the coastal communities' income is below the poverty line the turtle conservation can succeed only if it is done through means that protect people's livelihood rights rather than those of a single endangered species.

Another important finding is that there is a significant association between the level of interest in participatory turtle conservation and the level of education of the respondents. This highlights the need for education and training to coastal communities to conserve this species and others that are endangered.

Further, it was revealed that socio-economic characteristics such as age, education, experience in fishing and interest on nature had significant influence on willingness to support conservation of freshwater turtle programme.

Awareness programs and community participation in the conservation efforts are needed to protect the valuable endemic freshwater turtle and preserve the unique biodiversity which has potential in developing nature tourism in the Eastern Sri Lanka.

\section{REFERENCES}

Tisdell, C., Nantha, H.S and Wilson, C. (2005). Public valuation of and attitudes towards the conservation and use of the Hawksbill turtle: An Australian case study, Working Paper No.124 The University of Queensland. 
Economy and Environment Programme for Southeast Asia (EEPSEA). (2008). Willingness to pay for the conservation of endangered species in four Asian countries, Publication of International Development Research Centre (IDRC), Singapore.

International Union for the Conservation of Nature and Natural Resource (IUCN), Sri Lanka (1999). List of threatened species of Sri Lanka.

IUCN, (2004). Red list of threatened species. http//www.redlist.org

Kahneman, D. and Knetsch, J.L. (1992). Valuing public goods: The purchase of moral satisfaction. J. of Envt. Econ. \& Magt. 22: 57-70.

Kapurasinghe, T. (2006). Nature tourism in Rekawa with special reference to marine turtle conservation, Symposium on eco-tourism in Sri Lanka challenges and opportunities, Proceedings. Department of Wildlife Conservation $7^{\text {th }}$ July 2006, Colombo 07, Sri Lanka.

Loomis, J. and White. D. (1996). Economic benefits of rare endangered species summary and meta analysis. Ecological Econ. 18: 197-206.

Meylan, A. and Domnelly, M. (1999). Status justification for listing the Hawksbill turtle (Eretmochelys imbricate), as critically endangered on the 1996 IUCN Red List of Threatened Animals, Chelonian Conservation and Biology, 3: 200-224.

Turtle Conservation Project (2003). http//www.topsrilanka.org. 